\title{
Socio-politico - Pedagogical Problems of Language Teaching in Nigeria
}

\author{
AYEOMONI MOSES OMONIYI \\ $\mathrm{PhD}$, Senior Lecturer, Department of English \\ Obafemi Awolowo University, Ile-Ife, Osun State, Nigeria \\ Tel: 234-703-441-0685 E-mail: ayestyle@yahoo.com
}

Received: January 31, 2012

Accepted: February 25, 2012

Published: May 1, 2012

doi:10.5539/elt.v5n5p31

URL: http://dx.doi.org/10.5539/elt.v5n5p31

\begin{abstract}
The languages spoken in Nigeria do not only play significant roles in the socio-political life of the country, but also help in no small measure to unify or integrate the country that is so much diverse in all spheres of life. In realizing these multiplicity of roles the languages play in the country, the Government instituted and enacted a policy called language policy to control and plan the use, teaching and learning of the various languages that we have in the country. The languages are of three categories: the indigenous ones that are about 450 , the official one used for official purposes, which is English, and those that enjoy Foreign Language status, that is, Arabic and French. All these languages co-exist in the country. However, the Government policy on the use, teaching and learning of these languages is bedeviled with a lot of problems which range from inadequate materials and personnel to handle the teaching of the recommended ones in the policy to socio - political problems initiated and propagated by the various groups in the country. It is thus recommended that the Government of the Federation should revisit the policy on languages in the country, rework it to accommodate the socio/politico-cultural differences and realities of the nation in order that the country may tap and enjoy the intent benefits of the multiplicity of languages and cultures that the nation is endowed with.
\end{abstract}

Keywords: Language planning, Nigeria, Mother tongue, Second language, Teaching, Foreign languages

\section{Introduction}

Language plays a crucial role in social interaction and it is an all-important agent in the transmission of cultural and social values. It is shaped by the same political, social, and cultural forces which produce the world's diverse civilizations and cultures. The forces lead to the issue of "Language Planning" in Nigeria which can be described as a set of deliberate activities systematically designed to develop the language resources of a community in order to enhance the utilization of such resources for development. Various activities may take place while planning language: these may involve "status" planning which either widens or narrows the function of a language or dialect and the rights of those who use it, it could also involve dialects and the rights of those who use it, it could also involve "corpus" planning, which seeks to develop or improve the structure of a language or dialect.

\section{The Birth of Language Planning in Nigeria}

Some indigenous languages are not only taught in schools since Western type education was first introduced into the country, but also developed into native language status since political independence in 1960. As a result of development in this direction, Government policy on Education was being questioned. It was felt that English should be replaced as official language by one of our indigenous languages twenty years after independence (Bamgbose, 1976:12-13). It is viewed that more effort should be put into the teaching of the major indigenous languages to enable them to serve as alternatives to English as official means of communication in Government and Business (Osaji, 1979:159).

The overall effect of the suggestion and pressures of this kind was to bring about an important shift in the attitude of the Government, particularly at the Federal level, to the indigenous languages, since the Government is aware that a language is simultaneously a vehicle for a people's culture and a means of maintaining and indefinitely preserving that culture. The implication of this, which the Federal Government came to see and appreciate, is that if we are not to lose our national identity together with our rich indigenous cultures, then we must begin to pay more attention to the teaching of our indigenous cultures, then we must also begin to pay more attention to the teaching of our indigenous languages. In addition, on the relationship between language and culture, the Government also came to see the indigenous languages more clearly for variable and practical means of communication, which could easily be harnessed for effecting national integration, especially for a country still struggling to consolidate its independence. 
This consideration is made explicit in Section 1, paragraph 8 of NPE; as a result, the Federal Government began from the late 1970's onward to take official interest in, and make policy pronouncements on the teaching of the indigenous languages, instead of concerning itself solely with English. Thus, in an official document first published in 1977, revised in 1981, and titled Federal Republic of Nigeria National Policy on Education (NPE), the Federal Government for the first time laid it down as a policy for the whole country that:

(a) In primary school, which last six years, each child must study two languages, namely:

(i) His mother-tongue (if available for study) or an indigenous language of wider communication in his area of domicile; and

(ii) English language;

(b) In Junior Secondary School (JSS), which is of three years' duration, the child must study three languages viz:

(i) His mother-tongue (if available for study) or an indigenous language of wider communication in his area of domicile.

(ii) English language, and

(iii) Just any one of the three major indigenous languages in the country, namely, Hausa, Igbo and Yoruba, provided the Languages chosen is distinct from the child's mother-tongue;

(c) In Senior Secondary School (SSS), which also lasts three years, the child must study two languages, vis:

(i) An indigenous language, and

(ii) English language.

French and Arabic exist under the policy as language options at both the Junior and Secondary School levels, but there are no specific prescriptions in the policy document under reference for language education at the tertiary level of education, it is being felt, presumably, that the choice of subjects at that high level will necessarily be determined by the choices already made at the Primary and Secondary School levels.

Given what was said earlier, it can be seen that the teaching of English in the schools is of course not a new policy initiated by the NPE, so also the teaching of the indigenous languages, or at least the teaching of some of them, as mother tongues. These two types of languages have continuously featured in the country's schools since the middle of the nineteenth century. As it actually turns out, the only innovation in the NPE as far as language education is concerned is the teaching of the three major indigenous languages as second languages.

\section{Constitutional Backing for Language Planning}

The Government has continued to have inherent power to formulate policies regarding all aspects of life in the country, including that of educational policy on language. But in order that the Government's power in this particular matter is placed well beyond doubt or dispute, a brand new subsection was written into that portion of the country's 1999 constitution dealing with the educational objectives of state policy. The subsection in question, viz: sub-section 19(4), says that "Government shall encourage the learning of indigenous languages." It is providentially cast in such general terms as it allows easy reading and imposition of sanctions on defaulters. Thus, it sanctions the policy requirements for teaching Secondary School levels concerning the use of the child's mother tongue or, in the alternative, some indigenous languages of wider communication in his place of domicile.

\section{Mother Tongue Teaching}

The country is believed to have over 400 distinct indigenous languages (see Osaji, 1979; Bamgbose, 1971) and Adegbite (2010) says there are 500 of such languages. As each of the languages is by definition a mother tongue, in theory, they are all qualified to be taught as school subjects under the NPE policy on language education in Primary and Junior Secondary Schools. However, because most of them have sizeable numbers of speakers, it would not appear practicable to teach them as school subjects. For this reason, according to Brann (1977:47), the former National Language Center, now transformed into the current Language Development Center (LDC) and placed under the Nigerian Educational Research Council (NERDC), in 1976 suggested that, in addition to the three major languages, viz: Hausa, Igbo, and Yoruba, only nine of the remaining 397 or so indigenous languages in the country should be allowed to feature in the country's formal school system. They are: Edo, Fulfulde, Ibibio, Idoma, Igala, Ijaw, Kanuri, Nupe and Tiv.

Technically, very sound as that suggestion may actually be, it overlooks or completely ignores the degree of loyalty, some of the so called minority groups have towards their respective languages, as a result of which they appear ready to go to any length to ensure that such languages are formally taught to their children in school. One of such groups is formed by the Urhobos of Delta State, for whose language commercially printed Primers and Readers 
which have existed for about ten years now were established. Another group is that of the Ghotuos of Edo state, whose language, according to Elugbe (1991), is currently being reduced to writing preparatory for the production of Primers and Readers for teaching in Primary School. Some other groups that would appear to fall under this category are the Ebira of Kogi state, the Gwari of Niger, Kebbi, and Kaduna States, and the Jukun and Kutep of Taraba State. The loyalty that members of these groups have towards their individual languages, particularly in the case of the Jukun and Kutep, is so strong that it appears somewhat unlikely that they would be prepared to give up such languages altogether and adopt another indigenous language of wider communication instead. Accordingly, one would expect that, with time, the number of indigenous languages featuring in the nation's schools would rise beyond the twelve suggested by the former National Language Center.

Whatever the number of such languages that may eventually turn out to be, however, what seems very clear for now is that only very few of them are currently being adequately taught. The three major indigenous languages that have always been taught in the schools since the second half of the nineteenth century do not belong to this small group. The three languages are not only fully taught and examined as mother tongues in Primary and Secondary Schools, they, have for the past twenty or so years now, also being taught and examined as Single Honors subjects at first and higher degree levels, particularly in the case of Igbo, Yoruba and Hausa. Efik, Ibibio has also long featured as a school subject. It is, together with the three major languages, in the very small class of four indigenous languages examined for several decades now by the West African Examination Council (WAEC) and perhaps National Examination Council (NECO) and may by now, have started being examined at Certificate and first degree levels as well. Edo, Urhobo and Kanuri are currently taught for some years in Primary School, and are also taught at Certificate level and as part of first degree programme, all in an attempt to increase the number of people that could be employed and deployed to teach the three languages in Primary and Secondary Schools. The University of Maiduguri has a vision on its programme for teaching Fulfulde at preparatory level for teaching of the language in Primary School and Delta state University has commenced degree programme in Urhobo with a vision to train teachers to teach the language at both Primary and Secondary school levels. Similarly, some of the languages spoken in River state are taught at the University of Port-Harcourt.

Besides, some indigenous languages are taught at some State-owned Colleges of Education which do not include the languages that are regularly taught in the nation's schools. The reason for this is two-fold. First, only a few languages have enough materials to sustain teaching as they really ought to be taught at any educational level. Only Hausa, Igbo and Yoruba can be said to satisfy the set criterion; Efik, Ibibio would seem to satisfy that same criterion for being taught in Primary school and secondary School levels, but not up to the degree level. The remaining indigenous languages have a very long way to go in this regard, particularly for those of them that are yet to be reduced to writing. Secondly, only the three major indigenous languages can actually boast of enough teachers at all levels, While Efik, Ibibio may have teachers fully trained to teach that language at Primary and Secondary school levels, it would not appear to have enough people who could teach it at the tertiary level.

\section{The Teaching of Indigenous Languages as Second Languages in Nigeria}

The teaching of the three major indigenous languages as second languages is faced with both logistic and conceptual problems. To take the latter first, the National Policy on Education, as indicated earlier, requires each school child at the Junior Secondary School level to study one of those three languages in addition to his mother tongue. However, for practical reasons, as also indicated earlier, many school children cannot actually study their mother tongues but must have to study an indigenous language of wider communication instead, in Primary School as well as at the Junior Secondary school. This being the case, the language of wider communication that some of such children have to study as their mother tongue or first language (L1) is always one of the three major indigenous languages. This is also the case for children in Bauchi, Plateau, and Kaduna States, where Hausa would appear to serve as a language of wider communication, and in parts of Ondo, Edo and Kogi States, where Yoruba similarly serves as a language of wider communication. In this circumstance when children in these places have indigenous languages as their second language (L2), it then becomes a controversial issue in the country's language policy. Thus, Bamgbose (1977:23), for example, feels that such children, by having indigenous languages as their L1 would have satisfied both the letter and the spirit of Section 1, Paragraph 8 of NPE, which says:

In addition to appreciating the importance of languages in the educational process, and as a medium of preserving the people's culture, the Government considers it to be in the interest of national unity that each child should be encouraged to learn one of the three major languages other than his own mother-tongue. In this connection, the Government considers the three major languages in Nigeria to be Hausa, Igbo and Yoruba.

Awobuluyi (1966;17-18, 1979: 19; 1991b) on the other hand, is of the opinion that children in this category would only have satisfied the latter but not the spirit of the above quoted NPE language provision. The spirit of that 
provision, which derives from the needs of national unity, would seem to Awobuluyi require each school child in the country to communicate in indigenous language in the country other than his own. As a result, a child who studies only one of the indigenous languages as his first language is only exposed to his own cultural zone, and must therefore, study yet another major indigenous language as his second language in order to fulfill the real spirit of the language provision in question. What these clearly show is that substantial issue of the policy requires urgent clarification concerning the teaching of the three major languages as second languages.

Another relevant issue of the policy which has, however, tentatively unofficially been clarified is the Nigerian language required to be studied as a core subject at the Senior Secondary School level. As NPE does not openly indicate whether the language should be the child's L1 or his L2; different states in the country initially tended to interpret the language provision differently, to suit their purposes or biases. Later, however, the National Council on Education (NCE), the highest policy making body for Education in the country, ruled that the language must be the child's L2. But then, as pointed out in Awobuluyi (1991a), that the ruling of the NCE's is certain to prove very injurious to the growth and development of the three major languages, as it would in effect prevent them from being studied as L1 beyond the Junior Secondary School level.

Similarly,it affects all other indigenous languages that qualify to be studied as L1 in the nation's schools. To avoid this undesirable consequence, therefore, it has been suggested and also recommended to the Government in (Bamgbose and Akere 1991) that the single Nigerian language each child must study as a core subject at the Senior Secondary School level should either be his L1 or his L2. An early decision by the Government on this particular recommendation would completely eliminate the uncertainly and confusion that had hitherto characterized and bedeviled the teaching of the three major indigenous languages as L2 in country's secondary schools.

Lack of suitable pedagogical materials in the form of bilingual dictionaries and L2 pupil's and teacher's printed and/or tape-recorded texts, and an acute inadequacy of suitable trained L2 teachers for the three major indigenous languages have also constituted a very major problem militating against them as L2 in Secondary Schools throughout the country. It is not more than ten percent of the schools actually teach any of the languages as L2, ten years after the inauguration of the policy. A very noteworthy positive step was recently taken in this direction with the establishment in Aba, Imo State, of the Institute of Nigerian Languages, whose main functions, are to train L2 teachers and produce audio-visual materials for teaching the three major indigenous languages.

\section{The Teaching of English in Nigeria}

English, as indicated earlier, has for well over a century now continued to enjoy the pride of place in the nation's educational system, whereas the indigenous languages are rarely given more than three lesson periods a week on the school time table, English has up to five periods, and may even be given as many as seven or eight periods particularly in schools that prepare students for the Oral English examination. The language enjoys a profusion of pedagogical materials, and in this respect, contrasts sharply with the indigenous languages, the vast majority of which lack enough materials for teaching them as L1 even in Primary School.

Nevertheless, the teaching of the language in the nation's schools has its own problems too, just as the teaching of the indigenous languages, as indicated above. The most serious of such problems has to do with the quality of the teachers available to teach the language. Nearly, all the teachers are L2 speakers. The L2 speakers who were themselves taught by other L2 speakers who, in their turn, had learned the language imperfectly from other L2 speakers of English in the nation's schools today, have a fairly good command of the written and spoken forms of the language. To make matters worse still, such teachers have no training in contrastive Linguistics, and therefore are unable to understand and consequently devise effective pedagogical strategies for combating the mother-tongue induced kinds of learners' errors that recur in their pupils' written and oral performances in the languages. Another problem besetting the teaching of English relates to the books that are available locally in the language. Although the country has come a long way as the production of locally written texts in English, a lot of books particularly for children nevertheless still have to be imported from abroad. And such books are written and meant for other cultures than ours, one of their glaring shortcomings as books for the nation's schools is their cultural inappropriateness.

The teaching and examination syllabuses for the languages in Primary and Secondary Schools would appear to be over ambitious and therefore inappropriate for those two levels. Thus, primary school children being prepared for the Common Entrance Examination (used for determining admission into Secondary Schools) are expected to be able to show, for instance, what verb forms, whether singular or plural, the English conjunctions "and" and "as well as" which even most adult native speakers of English would not know and would therefore tend to avoid. Similarly, final year students in Secondary Schools are expected in their written English to display mastery and control of various register, even though their control of the language is so shaky that they scarcely can produce two to three grammatically flawless sentences at a time. While the latter two problems of suitable textual materials and 
appropriately syllabuses can perhaps easily be solved with hard work and determination, this is not the case for the unsatisfactory quality of the teachers of English available for the nation's schools. Ideally, the language ought to be taught in the country by specially trained native speakers, but given the current down-turn in the country's economy and the great demand for such teachers in other parts of the world such as the Gulf states that can afford better remunerations for them, these calibers are thus not available in the nation's schools. Accordingly, the possibility of effecting appreciable improvement in the quality of the English spoken in the country as a whole would appear very remote indeed, except a positive step is taken to ameliorate the problem.

\section{The Teaching of French and Arabic}

Although French and Arabic are elective subjects in the Secondary School Curriculum at both Junior and Senior levels. The Government is hardly aware of the problems that are likely to affect the teaching of both languages in the nation's schools, knowing that they are foreign languages for which pupils will not readily find models to interact with on a daily basis. However, the nation has now established two Special Language Villages, one for Arabic in the north-east of the country, and another for French in the South-west, where students can, over periods ranging from six months to one whole year, experience full immersion in those two languages. This approach to the teaching of French and Arabic, has the unexpected benefit of pointing at or highlighting what would appear to be a fundamental fallacy in the teaching of English based on the assumption that the language is a second rather than a foreign language in Nigeria. As long as this assumption continues to hold sway, with the result of proficiency attained in it by teachers and necessarily by their pupils also, will persist in the nation's school system, and this will continue to pose a big problem to the nation's educational planners.

\section{Conclusion}

In Nigeria, for instance, the government has made some policy statements which are enshrined in the constitution and the national policy on education document. In each case, the statement refers to the ideology of the government concerning the language planning in the country as follows:

Section 51 of the Nigeria Constitution of 1979, 1989 states thus:

"The business of National Assembly shall be conducted in English and Hausa, Igbo and Yoruba when adequate arrangements have been made therefore".

The statement above shows the intention of the Nigeria government towards assigning new role to the three major indigenous languages in order to promote them. It is also evident from the opinions reviewed in this paper, that all the languages taught in Nigeria (both indigenous and foreign) are bedeviled with one problem or the other, notable among the problems is the lack of competent qualified teachers to handle the teaching of the languages. Besides, there are also the inherent political and cultural problems affecting the teaching of the recommended languages in the policy. This is mainly due to the refusal of the minority groups in the country to embrace and accept the teaching and use of the three major languages. Each of the minority group is aspiring to develop their own languages to the recognizable level. As a result, it is viewed that there is the need to revisit the language policy once more with a view to reworking it, so that the languages so recommended may gain national acceptability, and for the country to benefit from the multiplicity of languages and cultures that the nation is naturally endowed with.

\section{References}

Adegbite, A. B. (2010). English Language Usage, Uses and Misuses in a non-host second Language context, Nigeria. Unpublished Inaugural Lecture Series 231, OAU, Ile-Ife.

Awobuluyi, O. (1979a). The New National Policy on Education in Linguistic Perspective. Ilorin, Nigeria: The University of Ilorin Press.

Awobuluyi, O. (1991b). Curricula and Syllabuses for Nigerian Languages. Appear in the proceedings of the Seminar on the Implementation of the Language Provisions of the national policy on Education edited by Bamgbose, A. and F. Akere.

Awobuluyi, O. (1991c). The National Language Question. A public lecture delivered under the Faculty of Arts Guest Lecture Series, University of Benin, Benin City, Edo State, Nigeria.

Bamgbose, A. (1977a). Towards an Implementation of Nigeria's Language Policy in Education. In Bamgbose, A. (Ed.), Language in Education in Nigeria, 1. Lagos, Nigeria: The National Language Center, Federal Ministry of Education (pp. 20-25).

Bamgbose, A., \& F. Akere. (Eds.). Summary of Recommendations from the Seminar on the Implementation of the Language Provisions of the National Policy on Education. Abuja, Nigeria: Nigerian Educational Research and Development Council, Federal Ministry of Education. 
Brann, C. M. B. (1979). Language Planning for Education in Nigeria: Some Demographic, Linguistics and Areal Factors. In Bambgose, A. (Ed.), Language in Education in Nigeria, 1. Lagos, Nigeria: The National Language Center, Federal Ministry of Education (pp. 47-61).

Elugbe, B. O. (1991). The Teaching of Minor (Regional) Nigeria Languages. In the Proceedings of the Seminar on the Implementation of the Language Provisions of the National Policy on Education edit by Bamgbose, A. and F. Akere.

Fafunwa A. B. (1974). History of Education in Nigeria. London: George Allen and Unwin.

Fafunwa, A. B. (1974). Federal Republic of Nigeria, 1981, National Policy on Education (Revised). Lagos, Nigeria: NERDC Press.

Fafunwa, A. B. (1974). Federal Republic of Nigeria, 1989, The Constitution of the Federal Republic of Nigeria. Ilorin, Nigeria: Woye Printers and Publishers.

Hair, P. E. H. (1967). The Early Study of Nigeria Languages: Essays and Bibliographies. Cambridge: Cambridge University Press.

Osaji, B. (1979). Languages Survey in Nigeria. International Center for Research on Bilingualism, Quebec, Canada. Taiwo, C. O. (1980). The Nigeria Education System. Lagos, Nigeria: Thomas Nelson (Nigeria) Limited. 